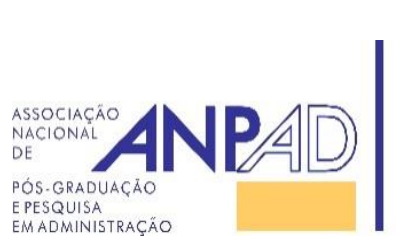

Available online at http://www.anpad.org.br/bar

BAR - Brazilian Administration Review

Rio de Janeiro, RJ, Brazil, v. 15, n. 4, e180152, 2018 http://dx.doi.org/10.1590/1807-7692bar2018180152

\title{
Editorial:
}

\section{Artificial intelligence and industry 4.0: The next frontier in organizations}

\author{
Alexandre Moreira Nascimento \\ University of Massachusetts Amherst, Amherst, MA, USA \\ Carlo Gabriel Porto Bellini \\ Universidade Federal da Paraíba, João Pessoa, PB, Brazil \\ Editor-in-chief, BAR - Brazilian Administration Review
}

In 2016, Professor Andrew Ng, from Stanford University, stated that artificial intelligence (AI) is the new electricity (Lynch, 2017). Such analogy illustrates the magnitude of the impacts of AI on businesses and society that are expected in coming years. That strong claim turned out to be very popular among AI researchers and practitioners, and has been frequently quoted in mass media.

AI is a field of human interest since the 1950s. The field started with an interest on the nature of intelligence and the possibilities offered by computer software, aiming at the development of software capable of emulating intelligence to complement or supplement human intelligence (Simon, 1995). The field has made significant progress, but a precise definition of AI is still a challenge for those involved with disseminating concepts and applications. Simon (1995) thinks of it as a branch of computer science interested in bringing to reality the properties of intelligence by means of synthetic intelligence, while Stone et al. (2016) see it as both a science and a set of computational technologies inspired by, but different from, the way people use their nervous system and body to feel, learn, reason, and act. There are at least five distinct perspectives on AI according to Sweeney (2003), who reviewed 996 definitions in the literature: human thinking, human behavior, ideal thinking, ideal behavior, and animal behavior.

AI is not mere theory and promise. Society has been benefiting from AI for decades. It impacts our lives significantly by fostering advances in many fields - such as in healthcare and business management. However, much of the progress is not reputed as AI impact due to an effect called odd paradox (Stone et al., 2016), that is, AI researchers create new technologies that are soon assimilated and appropriated by the application domains they are deemed useful for. As a consequence, proper recognition is not given to AI, and the AI researcher keeps working on the still unsolved hard problems (McCorduck, 2009), what in turn makes emerge the wrong perception that AI is futuristic and has not provided meaningful contributions yet.

Recently, much attention has been given to AI, as advancements pushed the boundaries of automation beyond the manual and operational activities. Automation has been targeting manual and operational tasks since the first industrial revolution, while the intellectual processes and tasks that are 
highly dependent on human cognition were left almost exclusively to skillful humans. Of course, it is debatable what an intellectual activity is, but here we take for granted that certain complex issues have not been the target of what we conceive as automation. Also, even if computers are able to make hard calculations and structured decisions, these are not as complex as dealing with abstract reasoning and unstable scenarios - that still require the presence of human agency. However, at this very moment, AI technologies worldwide are emulating human cognition at increasingly higher levels of abstraction and adaptation capabilities. This creates tremendous possibilities in a still idyllic world, such as the computerization of complex tasks in marketing, finance, law, human resources, operations, and strategy, what in turn would free people to work on even more complex issues - or just enjoy life and think of the unsolved questions of humankind. In fact, even creative processes like the first cut of a film have been already done by machines, such as IBM Watson (Cox, 2018).

Since the first industrial revolution, technology has been also changing the nature of work, and the impact of $\mathrm{AI}$ in this domain is arguably significant. It is estimated that $47 \%$ of jobs in the USA, and a higher percentage in developing countries, will be at risk with AI advancements (Frey \& Osborne, 2016). The growing concerns on this topic put it in the spotlight of the 2016 World Economic Forum. However, the impacts of AI progress go beyond the changes in the nature of work, but also regarding the economic mechanisms and business models (Loebbecke \& Picot, 2015).

Another related discussion involving AI is how companies will be affected depending on their abilities to understand, adopt and benefit from the technological advances. In this sense, established companies often struggle to adapt their business models to new economic mechanisms (Loebbecke \& Picot, 2015). For example, many players in a variety of industries suffered to adapt to the Internet, among them the traditional retail sector, which is still facing losses and adaptation costs. Only in the USA, 57 chains, including Sears and Toys'R'Us, filed Chapter 11 bankruptcy protection since 2015. However, some thinkers see this as just the beginning of the retail apocalypse (Townsend, Surane, Orr, \& Cannon, 2017), with AI potentially being the key driver of the new organizational model.

BAR is no alien to an AI-shaped world. BAR is continuously interested in discussing technological progress, as the organizational routines are inevitably impacted by technology in diverse ways and regardless of how technology was originally conceived. Technology diffusion effects along with the adaptation of technology by users and the emergence of unanticipated applications create new realities that eventually reach the organizational realm with promises of significant gains. This is the case, for instance, of virtual social networking, which was initially planned to be a digital version of the world of personal connections but was soon seen by organizations as an opportunity (and soon after, a need) to interact with the market through richer channels. In fact, the interplay of technology and organizations has been popular among organization scholars for a long time, especially since the landmark work of Woodward (1965) on the oftentimes intriguing (Donaldson, 1976) relationships of production technology, organizational structure, and organizational performance.

Thus, the new challenges and opportunities offered by novel technologies seed reflections among users, researchers and practitioners, with particular effects for public and business administration. In the case of AI, we see a promising avenue for organization studies in the application of intelligent technologies to leverage what is known as industry 4.0, or the fourth industrial revolution - one that comes after the water and steam revolution, the electric power revolution, and the digital revolution. The fourth revolution is heavily based on the integration of physical, digital and biological structures, especially the Internet and the industrial value chain (Hermann, Pentek, \& Otto, 2016), with significant impacts on people, businesses and governments (Schwab, 2015). Industry 4.0 is also seen as closely related to advances in AI (Lee, Davari, Singh, \& Pandhare, 2018; China Daily, 2018), what makes us confident that great opportunities exist for research on the confluence of intelligent technologies, the development of human skills, and new organizational configurations, routines and expected outcomes. We thus invite the BAR community to consider AI and industry 4.0 as topics to advance scholarly knowledge on the next generation of organizations and administrative practice. 


\section{References}

China Daily. (2018, April 27). AI seen as driving force in industry 4.0. Retrieved from http://www.chinadaily.com.cn/a/201804/27/WS5ae29547a3105cdcf651ae80.html

Cox, C. (2018). Autonomous exchanges: Human-machine autonomy in the automated media economy (Doctoral dissertation). Department of Moving Image Studies, Georgia State University, Atlanta, GA, USA.

Donaldson, L. (1976). Woodward, technology, organizational structure and performance - A critique of the universal generalization. Journal of Management Studies, 13(3), 255-273. https://doi.org/10.1111/j.1467-6486.1976.tb00902.x

Frey, C. B., \& Osborne, M. A. (2016). Technology at work v2.0: The future is not what it used to be. City GPS: Global Perspective \& Solutions.

Hermann, M., Pentek, T., \& Otto, B. (2016, January 5-8). Design principles for industrie 4.0 scenarios. Proceedings of the Hawaii International Conference on System Sciences, IEEE, Koloa, HI, USA, 49. https://doi.org/10.1109/HICSS.2016.488

Lee, J., Davari, H., Singh, J., \& Pandhare, V. (2018). Industrial artificial intelligence for industry 4.0$\begin{array}{lllll}\text { based manufacturing } & \text { systems. }\end{array}$ https://doi.org/10.1016/j.mfglet.2018.09.002

Loebbecke, C., \& Picot, A. (2015). Reflections on societal and business model transformation arising from digitization and big data analytics: A research agenda. Journal of Strategic Information Systems, 24(3), 149-157. https://doi.org/10.1016/j.jsis.2015.08.002

Lynch, S. (2017, March 11). Andrew Ng: Why AI is the new electricity. Retrieved from https://www.gsb.stanford.edu/insights/andrew-ng-why-ai-new-electricity

McCorduck, P. (2009). Machines who think: A personal inquiry into the history and prospects of artificial intelligence. Wellesley, MA, USA: AK Peters/CRC Press.

Schwab, K. (2015, December 12). The fourth industrial revolution: What it means and what to respond. Foreign Affairs. Retrieved from https://www.foreignaffairs.com/articles/2015-12-12/fourthindustrial-revolution

Simon, H. A. (1995). Artificial intelligence: An empirical science. Artificial Intelligence, 77(1), 95-127. https://doi.org/10.1016/0004-3702(95)00039-h

Stone, P., Brooks, R., Brynjolfsson, E., Calo, R., Etzioni, O., Hager, G., et al. (2016). Artificial intelligence and life in 2030.2 Retrieved from https://ai100.stanford.edu/sites/default/files/ai_100_report_0831fnl.pdf

Sweeney, L. (2003, January). That's AI? A history and critique of the field (Technical Report CMU-CS03-106). Carnegie Mellon University, School of Computer Science, Pittsburgh, PA, USA. Retrieved from https://dataprivacylab.org/projects/thatsai/paper.pdf

Townsend, M., Surane, J., Orr, E., \& Cannon, C. (2017, November 8). America's "retail apocalypse" is really just beginning. Retrieved from https://www.bloomberg.com/graphics/2017-retail-debt/

Woodward, J. (1965). Industrial organization: Theory and practice. London, UK: Oxford University Press. 


\section{Authors}

\section{Alexandre Moreira Nascimento}

Visiting scholar, Isenberg School of Management, University of Massachusetts Amherst 121 Presidents Dr, 01003, Amherst, MA, USA

alexandre.nascimento@sloan.mit.edu

(D) https://orcid.org/0000-0002-4342-6453

\section{Carlo Gabriel Porto Bellini}

Associate professor, Department of Management, Universidade Federal da Paraíba

Campus Universitário I, Jardim Cidade Universitária, 58059-900, João Pessoa, PB, Brazil bar-eic@ anpad.org.br

(iD) https://orcid.org/0000-0001-5809-3172 